\title{
THE LOCATION OF
}

\section{KANT'S REFUTATION OF IDEALISM}

In the second edition of the Critique of Pure Reason, Kant inserts an entirely new section: the Refutation of Idealism. Here he defends our claim to know that external, spatially extended objects such as apples, books and cups of tea actually exist. He constructs what he describes as 'a strict proof... of the reality of outer intuition' (Bxxxix). There are many difficult questions about this section of the Critique. There are questions about the structure of Kant's proof, about his motivation for adding it to the second edition, and about its relationship to the treatment of idealism in the Fourth Paralogism of the first edition. In this article I am going to focus on a question about the location of the Refutation of Idealism. Why does Kant add it to the second edition of the Critique at the end of his elucidation of the Second Postulate of Empirical Thinking in General? ${ }^{1}$

Kant appears to provide an answer to this question in a sentence that he adds at the end of his elucidation of the Second Postulate, just before the Refutation of Idealism itself. He writes: 'A powerful objection against these rules for proving existence indirectly is made by idealism, the refutation of which is here in its right place' (B274). ${ }^{2}$ But it isn't easy to think of a satisfactory explanation for the location of the Refutation of Idealism that is also plausibly expressed by this sentence. ${ }^{3}$ One possible explanation would be that the Refutation of Idealism and the Second Postulate are both concerned with our knowledge of the actual existence of objects. Whereas the Second Postulate is a principle that specifies the conditions under which we can know that a given object actually exists, 
the Refutation of Idealism is a proof that the objects that we can know actually exist include external, spatially extended objects such as apples, books and cups of tea. The problem is that this explanation isn't plausibly expressed by the sentence that Kant inserts at the end of his elucidation of the Second Postulate. It doesn't refer to any 'powerful objection... made by idealism', nor does it refer to any 'rules for proving existence indirectly'. Now one of the parts of the Second Postulate is the claim that the laws of cause and effect, inherence and reciprocal interaction are the rules for proving existence indirectly. So an explanation that is plausibly expressed by the sentence Kant adds at the end of his elucidation of the Second Postulate is that the Refutation of Idealism is his response to the objection that these laws must be false since idealism is true. The problem with this explanation is that it is open to a serious objection. One of the laws of cause and effect, inherence and reciprocal interaction serves as a premise of the Refutation of Idealism, so Kant cannot use the Refutation of Idealism to respond to an objection against these laws on pain of circularity.

My aim in this article is to provide an explanation for the location of the Refutation of Idealism that is plausibly expressed by the sentence that Kant inserts at the end of his elucidation of the Second Postulate and that is not open to serious objections. I shall argue that the powerful objection to which the Refutation of Idealism is Kant's response is not an objection against the laws of cause and effect, inherence and reciprocal interaction, but rather an objection against the Second Postulate. In particular, I shall argue that it is an objection against the claim that the laws of cause and effect, inherence and reciprocal interaction are the rules for proving existence indirectly. By this I mean 
that it is an objection against the claim that if we cannot perceive a given object, then we can know that this object actually exists only if the following condition is satisfied: there is some other object such that (a) we can perceive this other object, and (b) it would violate the laws of cause and effect, inherence or reciprocal interaction if this other object actually existed, but the object that we cannot perceive did not actually exist. Moreover, I shall argue that the powerful objection made by idealism against the Second Postulate is not that the Second Postulate must be false since idealism is true, but rather that the Second Postulate must be false since otherwise idealism is true. The objection is that the Second Postulate is too restrictive, since it rules out the possibility of knowing that external, spatially extended objects actually exist. The objection turns on the assumption that we cannot perceive external, spatially extended objects. I shall argue that it is precisely by establishing that we can perceive external, spatially extended objects that the Refutation of Idealism serves as a response to this objection.

At the beginning of the Postulates of Empirical Thinking in General, Kant introduces the Second Postulate as the principle that '[what] is connected with the material conditions of experience (sensation) is actual' (A218/B266). ${ }^{4}$ One important question regarding this principle is whether it should be interpreted as a metaphysical claim about the conditions under which an object actually exists, or as an epistemological claim about the conditions under which we can know that a given object actually exists. Another important question 
has to do with the material conditions of experience. Kant thinks that an object is connected with the material conditions of experience if we can perceive this object. But he doesn't think that an object is connected with the material conditions of experience only if we can perceive this object. The second question is under what conditions Kant thinks that an object that we cannot perceive is nonetheless connected with the material conditions of experience.

I propose that the Second Postulate should be understood as the following claim:

We can know that an object $x$ actually exists if and only if either (1) we can perceive $x$ or (2) there is some other object $y$ such that (a) we can perceive $y$, and (b) it would violate the laws of cause and effect, inherence or reciprocal interaction if $y$ actually existed, but $x$ did not actually exist. ${ }^{5}$

Kant's elucidation of the principle strongly suggests that it is intended as an epistemological claim about the conditions under which we can know that an object actually exists. He writes that '[the] postulate for cognizing the actuality of things requires perception... not indeed the immediate perception of the object itself the existence of which is to be cognized, but still the connection of this object with some actual perception in accordance with the Analogies of Experience' (A225/B272). He also writes that although 'perception... is the unique characteristic of actuality', 'the existence of a thing can be cognized prior to the perception of the thing, and so comparatively $a$ priori, if only it is connected with some perceptions in accordance with the principles of 
the empirical connection of perceptions (the Analogies)' (A225/B273). ${ }^{6}$ These passages also suggest that an object that we cannot perceive is connected with the material conditions of experience if and only if there is some other object such that (a) we can perceive this other object, and (b) this other object is connected to the object that we cannot perceive in accordance with the Analogies of Experience. Kant's example of an object that is connected with the material conditions of experience in this way is a 'magnetic matter permeating all bodies', which he claims we can know actually exists 'from the perception of attracted iron filings, although an immediate perception of this matter is impossible for us given the constitution of our senses' (A226/B273). ${ }^{7}$ Now, the claim that an object we cannot perceive is connected to an object we can perceive in accordance with the Analogies of Experience can be interpreted in more than one way. First, it can be interpreted as the claim that if the object we can perceive actually existed, but the object we cannot perceive did not actually exist, then this would violate the Analogies of Experience (i.e. it would imply that there was a change that was not an alteration, or an event that lacked a cause, or a failure of reciprocal interaction). Second, it can be interpreted as the claim that if the object we can perceive actually existed, but the object we cannot perceive did not actually exist, then this would violate the laws of cause and effect, or inherence, or reciprocal interaction, whether the general a priori principles of cause and effect, inherence and reciprocal interaction, or more specific empirical laws. The problem with the first interpretation is that it makes the Second Postulate implausibly restrictive. Suppose I hear the doorbell ring. It would violate the Analogies of Experience if nothing had caused the doorbell to ring. But it would not violate the 
Analogies of Experience had this ring not been caused by a person outside pressing the button. So it is an implication of the Second Postulate according to the first interpretation that I cannot know that there is a person outside pressing the button unless I can perceive them. To avoid this implication, I have chosen the second interpretation. ${ }^{8}$ There is also textual evidence to support this interpretation. Kant writes at one point that 'our cognition of the existence of things reaches as far as perception and what is appended to it in accordance with empirical laws' (A226/B273, my emphasis), which suggests that he isn't just thinking about the general a priori principles of causality, inherence and reciprocal interaction. ${ }^{9}$

There are two points about the Second Postulate to which I want to draw particular attention. First, it is an implication of the Second Postulate that there is both a direct and an indirect way in which we can know that a given object actually exists. Suppose I can know that a given object actually exists because I can perceive it. Then my knowledge that this object actually exists is direct in the sense that it would not be based on my knowledge that any other object actually exists. By contrast, suppose I can know that a given object actually exists because there is some other object such that (a) I can perceive this other object, and (b) it would violate a law of cause and effect, or a law of inherence or reciprocal interaction, if this other object actually existed, but the object that I cannot perceive did not actually exist. Then my knowledge that the first object actually exists is indirect in the sense that it is based on my knowledge of the actual existence of some other object.

Second, it is an implication of the Second Postulate that our knowledge of the 
actual existence of objects is restricted to what we can perceive, and whatever is connected to what we can perceive in accordance with the Analogies of Experience. As I have already mentioned, Kant writes that 'our cognition of the existence of things reaches as far as perception and what is appended to it in accordance with empirical laws' (A226/B273). So it is an implication of the Second Postulate that the objects that we can know actually exist do not include any non-empirical, super-sensible objects such as Cartesian souls or Leibnizian monads.

One possible explanation for the location of Kant's Refutation of Idealism is that both the Refutation of Idealism and the Second Postulate are concerned with our knowledge of the actual existence of objects. ${ }^{11}$ A more precise version of this explanation is that both the Refutation of Idealism and the Second Postulate are concerned with the extent of our knowledge of the actual existence of objects. They are both concerned with the question: which objects can we know actually exist? Part of the lesson of the Second Postulate is that the objects that we can know actually exist do not include any nonempirical, super-sensible objects such as Cartesian souls or Leibnizian monads. And part of the lesson of the Refutation of Idealism is that the objects that we can know actually exist do include external, spatially extended objects such as apples and books and cups of tea.

It is not unreasonable to suppose that Kant inserts the Refutation of Idealism at the end of his elucidation of the Second Postulate because they are both concerned with our knowledge of the actual existence of objects - or, more precisely, with the question which objects we can know actually exist. The trouble with this explanation, as I 
mentioned in my introduction, is that it is not plausibly expressed by the sentence that Kant inserts at the end of his elucidation of the Second Postulate. The sentence in question refers to a 'powerful objection... made by idealism' (B274). It also refers to 'rules for proving existence indirectly' (B274). ${ }^{12}$ So there is clearly more to Kant's reason for adding the Refutation of Idealism at the end of his elucidation of the Second Postulate than the fact that both the Refutation of Idealism and the Second Postulate are concerned with our knowledge of the actual existence of objects. ${ }^{13}$

\section{II}

In Section I, I discussed the proposal that Kant inserts the Refutation of Idealism at the end of his elucidation of the Second Postulate simply because these sections of the Critique are both concerned with our knowledge of the actual existence of objects. As I said, this explanation is not plausibly expressed by the sentence that Kant inserts at the end of his elucidation of the Second Postulate: 'A powerful objection against these rules for proving existence indirectly is made by idealism, the refutation of which is here in its right place' (B274). In this section I am going to consider an explanation for the location of the Refutation of Idealism that is plausibly expressed by this sentence.

This sentence raises two important questions. The first is what exactly Kant means by a powerful objection 'against these rules for proving existence indirectly', and the second is what exactly Kant means by a powerful objection against these rules for proving existence indirectly 'made by idealism'. Now one of the claims that Kant makes 
in his elucidation of the Second Postulate is that if we cannot perceive a given object, then we can know that this object actually exists only if there is some other object such that (a) we can perceive this other object, and (b) it would violate a particular set of rules, viz. the laws of cause and effect, inherence and reciprocal interaction, if this other object actually existed, but the object that we cannot perceive did not actually exist. So it is a reasonable assumption that what Kant means by a powerful objection 'against these rules for proving existence indirectly' is a powerful objection against the laws of cause and effect, inherence and reciprocal interaction. He means a powerful objection against what he has just specified in his elucidation of the Second Postulate as the rules for proving existence indirectly. It is also a reasonable assumption that what Kant means by a powerful objection against these rules for proving existence indirectly made by idealism is a powerful objection on the part of idealism: the objection that these rules must be false since idealism is true. If these assumptions are correct, then Kant's claim in the sentence that he adds at the end of his elucidation of the Second Postulate is that he has inserted the Refutation of Idealism at this particular point in the Critique because it is his response to the objection that the laws of cause and effect, inherence and reciprocal interaction must be false since idealism is true.

This explanation for the location of the Refutation of Idealism is based on a plausible interpretation of the sentence that Kant inserts at the end of his elucidation of the Second Postulate. ${ }^{14}$ However, there is good reason to reject it. A less serious objection is that this interpretation conflicts with the widespread assumption that the material in the Critique of Pure Reason is organized in a highly systematic fashion. Kant 
adds the Refutation of Idealism to the section of the first Critique the subject (and title) of which is the Postulates of Empirical Thinking in General. He does not add it to the earlier section of the first Critique the subject of which is the laws of cause and effect, inherence and reciprocal interaction, viz. the Analogies of Experience. It might be thought that if the Refutation of Idealism is Kant's response to an objection against the laws of cause and effect, inherence and reciprocal interaction, then this earlier section of the first Critique is a more appropriate place for it. If the Refutation of Idealism is Kant's response to an objection against the laws of cause and effect, inherence and reciprocal interaction, then he should not have inserted it at the end of his elucidation of the Second Postulate. Henry Allison has stressed a related point. ${ }^{15}$ The earlier section of the first Critique the subject (and title) of which is the Analogies of Experience consists of what are clearly marked as proofs of the Analogies of Experience. ${ }^{16}$ But if Kant thinks that he has succeeded in proving the Analogies of Experience by the end of this earlier section, he cannot think that the Analogies of Experience are open to a powerful objection in the Postulates of Empirical Thinking in General. If the Refutation of Idealism is Kant's response to a powerful objection against the laws of cause and effect, inherence and reciprocal interaction in general, then it is only at the end of the Refutation of Idealism that his proof of the Analogies of Experience has been completed. Although it would be reasonable for Kant to provide a proof of the Analogies of Experience based on premises that are only subsequently proved in a later section of the Critique, he might at least have been expected to point out in the earlier section that his proofs are provisional, pending the success of his refutation of idealism. 
Even setting these systematic considerations to one side, there is a serious problem with the present interpretation. The second premise of Kant's argument in the Refutation of Idealism is that '[all] time-determination presupposes something persisting in perception' (B275). It is widely accepted that this premise is the principle of the First Analogy, which is the most general law of inherence. ${ }^{18}$ So it appears that Kant's argument against idealism is based on the premise that at least one of the laws of cause and effect, inherence and reciprocal interaction is true. But it is an implication of the present explanation for the location of the Refutation of Idealism that Kant's argument for the laws of cause and effect, inherence and reciprocal interaction in general is based on the premise that idealism is false. So it is an implication of the present explanation that Kant is guilty of circular reasoning. His Refutation of Idealism is based on one of the laws of cause and effect, inherence and reciprocal interaction, and his argument for these laws is based on his Refutation of Idealism. I submit that this is a decisive objection to the present explanation for the location of the Refutation of Idealism. Kant does not add the Refutation of Idealism at the end of his elucidation of the Second Postulate because it is his response to the objection that the laws of cause and effect, inherence and reciprocal interaction must be false since idealism is true.

\section{III}

Luigi Caranti thinks that Kant's claim in the sentence that he inserts at the end of his elucidation of the Second Postulate is 'inaccurate and perhaps even misleading' (2007: 
129). He suggests that 'Kant's stated justification for placing the Refutation where he does... is plausible only because there is a vague resemblance between the inference Kant defends (from perceived to unperceived) and the inference the sceptic attacks (from a representation to its object)' (2007: 129). According to Caranti, the powerful objection to which the Refutation of Idealism is Kant's response is an objection against the Second Postulate. In particular, it is an objection against the claim that we can know that an object actually exists if we can perceive it. The first premise of the objection is that our perception of an object is sufficient for us to know that this object actually exists only if our perception of this object is direct in the sense that it does not depend upon some sort of causal inference 'from a mental state to the object that supposedly caused it' (2007, 129). The second premise of the objection is that our perception of objects is not direct in this sense. As Caranti puts it, '[for] the idealist, even when I directly perceive an object [by which he means: even when I know that an object actually exists, but not because of the connection between the actual existence of this object and the actual existence of some other object], its existence is inferred indirectly' (2007: 129). The conclusion of the objection is that our perception of an object is not sufficient for us to know that this object actually exists. It is not true that if we can perceive an object, then we can know that this object actually exists.

According to Caranti, Kant thinks that the fact that an object is 'bound up with sensation' is a 'reliable mark of [its] actuality' (2007: 130). The idealist objects to this claim by questioning 'the reliability of a sensation for determining an existence - that is, the immediacy of outer perception' (2007: 130). Caranti thinks that Kant adds the 
Refutation of Idealism at the end of his elucidation of the Second Postulate precisely because it is his response to this objection against the claim that if we can perceive an object, then we can know that it actually exists. He concludes that it is... only natural that Kant places what can serve as a defence of his Postulate - the Refutation immediately after the exposition of the Postulate itself (2007:130). ${ }^{21}$

This explanation for the location of the Refutation of Idealism is more plausibly expressed by the sentence that Kant inserts at the end of his elucidation of the Second Postulate than the explanation that I discussed in Section I, since it treats the Refutation of Idealism as Kant's response to a 'powerful objection... made by idealism'. And it is not open to the same objections as the explanation that I discussed in Section II, since it treats the Refutation of Idealism as Kant's response to an objection against the Second Postulate as opposed to an objection against the laws of cause and effect, inherence, and reciprocal interaction. The problem with this explanation is that it still doesn't quite fit the sentence that Kant inserts at the end of his elucidation of the Second Postulate. This is a point that Caranti is prepared to accept. Kant clearly indicates that the powerful objection is against the part of the Second Postulate that has to do with knowing that objects actually exist indirectly. But according to Caranti, the powerful objection is against the part of the Second Postulate that has to do with knowing that objects actually exist directly, viz. the claim that we can know that a given object actually exists if we can perceive it.

Another recent explanation for the location of Kant's Refutation of Idealism is due to Ralf Bader. Bader's answer to the question why Kant adds the Refutation of Idealism to the Critique at the end of his elucidation of the Second Postulate has three parts. First, 
Bader makes the familiar point that the Refutation of Idealism and the Second Postulate are both concerned with the actual existence of objects. Second, he suggests that Kant's argument in the Refutation of Idealism 'appeals to the conditions for determining one's existence in time' (2012: 69), which is an application of the schema of the concept of actuality. Third, Bader argues that the Second Postulate is 'directly threatened by problematic idealism', inasmuch as it 'requires that something be given by perception rather than merely imagined' (2012: 69). As Bader also puts it, '[if] nothing were to be given in perception, but instead everything were to be a product of the imagination, then this Postulate would become irrelevant' (2012: 69). It is not clear exactly what Bader means by the relevance of the Second Postulate. His assumption seems to be that if idealism is true then it follows that no objects satisfy what are, according to the Second Postulate, the conditions under which we can know that a given object actually exists, and this is as much as to say that the Second Postulate is irrelevant. One problem with this assumption is that if idealism is true, then it doesn't immediately follow that no objects satisfy what are, according to the Second Postulate, the conditions under which we can know that a given object actually exists. After all, there might be objects that are not external - in particular, internal objects - that still satisfy these conditions. ${ }^{22}$ Another problem with Bader's interpretation is that it is not clear why it is such a powerful objection against the Second Postulate that it is irrelevant in this sense. After all, the Second Postulate might be irrelevant in this sense, but nonetheless true. ${ }^{23}$

There is one final explanation for the location of the Refutation of Idealism that it is important to consider. According to this explanation, the powerful objection to which 
the Refutation of Idealism is Kant's response is an objection against a particular argument for the Second Postulate. The first premise of the argument is that it is a condition of the possibility of our experience of external, spatially extended objects that the Second Postulate is true. The second premise of the argument is that we have experience of external, spatially extended objects. From these premises it follows that the Second Postulate is true. The powerful objection against this argument for the Second Postulate is that we do not have experience of external, spatially extended objects. Since we do not have experience of external, spatially extended objects, the fact that the truth of the Second Postulate is a condition of the possibility of our experience of external, spatially extended objects gives us no reason to think that the Second Postulate is true. According to the present explanation, Kant inserts the Refutation of Idealism at the end of his elucidation of the Second Postulate precisely in order to respond to this objection against his argument for the Second Postulate. ${ }^{24}$

This is a simple and in some ways attractive explanation for the location of the Refutation of Idealism. But it is also open to at least two objections. The first objection is that there is no clear evidence that Kant's argument for the Second Postulate is based on the premise that the truth of the Second Postulate is a condition of the possibility of our experience of external, spatially extended objects. There is plenty of evidence that Kant's arguments in the Analytic of Principles are supposed to establish that the Pure Principles of the Understanding are conditions of the possibility of experience. ${ }^{25}$ But it is not at all clear that what Kant means by experience in this context is experience of external, spatially extended objects. ${ }^{26} \mathrm{He}$ could just mean experience in general. And an idealist 
does not deny that we have experience. This is clear from Kant's remark that his strategy in the Refutation of Idealism is to show 'that our inner experience, undoubted by [the problematic idealist], is possible only on the presupposition of outer experience' (B275). If Kant's argument for the Second Postulate is based on the premise that it is a condition of the possibility of experience in general that the Second Postulate is true, the idealist will not object to this argument on the grounds that we do not have experience.

The second objection against the present explanation is a one that I have already mentioned. If this explanation is correct, then the powerful objection to which the Refutation of Idealism is Kant's response is not an objection against the part of the Second Postulate that has to do with the 'rules for proving existence indirectly', but rather an objection against Kant's argument for the Second Postulate as a whole. So once again the explanation doesn't quite fit the sentence that Kant inserts at the end of his elucidation of the Second Postulate.

\section{IV}

So far in this article, I have discussed five possible explanations for the location of Kant's Refutation of Idealism. According to the first explanation, which I discussed in Section I, the reason why Kant inserts the Refutation of Idealism at the end of his elucidation of the Second Postulate is that both of these sections are concerned with our knowledge of the actual existence of objects. According to second explanation, which I discussed in Section II, and which is based on an interpretation of Kant's claim that '[a] powerful objection 
against these rules for proving existence indirectly is made by idealism' (B274), the reason why Kant inserts the Refutation of Idealism at the end of his elucidation of the Second Postulate is that it is his response to the objection that the laws of cause and effect, inherence and reciprocal interaction must be false since idealism is true. According to the three explanations that I discussed in Section III, Kant inserts the Refutation of Idealism at the end of his elucidation of the Second Postulate because it serves as his response to the objection that the Second Postulate is false, or irrelevant, or that his argument for the Second Postulate is unsound, since idealism is true.

According to the explanation that I am about to suggest, the Refutation of Idealism is Kant's response to an objection against the Second Postulate - and, in particular, an objection against the part of the Second Postulate that specifies the conditions under which we can know that an object that we cannot perceive actually exists. As I explained in Section I, what this part of the Second Postulate tells us is that if we cannot perceive a given object, then we can know that this object actually exists if and only if there is some other object such that (a) we can perceive this other object, and (b) it would violate the laws of cause and effect, inherence or reciprocal interaction if this other object actually existed, but the object we cannot perceive did not actually exist. The objection against this part of the Second Postulate is not that it must be false since idealism is true, but rather that it must be false since otherwise idealism is true. The objection is that the Second Postulate is too restrictive a claim about the conditions under which we can know that a given object actually exists. There are objects that we can know actually exist, in spite of the fact that (1) we cannot perceive these objects and (2) there 
are no other objects such that (a) we can perceive these other objects and (b) it would violate the laws of cause and effect, inherence or reciprocal interaction if these other objects actually existed, but the objects we cannot perceive did not actually exist. The objects in question are external, spatially extended objects.

Before I state the objection more precisely, it will be helpful to distinguish three possible responses to the question whether we can know that external, spatially extended objects actually exist. First, there is idealism, according to which we cannot know that external, spatially extended objects actually exist. Second, there is direct realism, according to which we can know that external, spatially extended objects actually exist directly, on the basis that we can perceive these objects. Third, there is indirect realism. According to indirect realism, we cannot know directly that external, spatially extended objects actually exist, since the only objects that we can know directly actually exist are the representations in our minds. However, we can still know that external, spatially extended objects actually exist, since it would violate certain principles if the representations in our minds actually existed, but external, spatially extended objects did not actually exist. We can know that external, spatially extended objects actually exist indirectly. It is worth emphasizing that direct realists may also claim that we can know that external, spatially extended objects actually exist indirectly. What is distinctive about indirect realism is the claim that this is the only way in which we can know that external, spatially extended objects actually exist.

According to the explanations for the location of the Refutation of Idealism that I discussed in the previous section, the objection to which the Refutation of Idealism is 
Kant's response is an objection against the Second Postulate on the part of idealism. That is the sense in which it is an objection 'made by idealism'. According to the explanation that I want to propose, the objection to which the Refutation of Idealism is Kant's response is an objection against the Second Postulate on the part of indirect realism. For this reason, I am going to call it the Indirect Realist Objection against the Second Postulate. Here is how it goes.

(1) We cannot know directly that external, spatially extended objects actually exist.

(2) If we cannot know directly that external, spatially extended objects actually exist, and the laws of cause and effect, inherence and reciprocal causal interaction are the rules for proving existence indirectly, then we cannot know indirectly that external, spatially extended objects actually exist.

(3) We can know that external, spatially extended objects actually exist only if either (a) we can know directly that external, spatially extended objects actually exist, or (b) we can know indirectly that external, spatially extended objects actually exist. 
(4) If the laws of cause and effect, inherence and reciprocal causal interaction are the rules for proving existence indirectly, then we cannot know that external, spatially extended objects actually exist.

But

(5) We can know that external, spatially extended objects actually exist.

So

(6) The laws of cause and effect, inherence and reciprocal causal interaction are not the rules for proving existence indirectly.

Taken together, premises (1) and (5) of this objection express indirect realism. The motivation for premise (2) runs as follows. Suppose that we cannot know directly that external, spatially extended objects actually exist. Then the only objects that we can know directly actually exist are the representations in our minds. Now, suppose that the laws of cause and effect, inherence and reciprocal causal interaction are the rules on the basis of which we can know that objects actually exist indirectly. Then we can know indirectly that external, spatially extended objects actually exist only if it would violate the laws of cause and effect, inherence or reciprocal interaction if the representations in our minds actually existed, but external, spatially extended objects did not actually exist. The problem is that it would not violate these laws if the representations in our own minds actually existed, but external, spatially extended objects did not actually exist. It is 
entirely possible that the representations in our minds are caused by something other than external, spatially extended objects. As Kant puts it in the Refutation of Idealism, the existence of spatially extended objects can be inferred from the existence of representations in our minds 'only unreliably, because the cause of the representations, which we perhaps falsely ascribe to outer things, can also lie in us' (B276). ${ }^{27}$ It is also entirely possible that the representations in our minds inhere in something other than an external, spatially extended object. So if we cannot know that directly that external, spatially extended objects actually exist, and the laws of cause and effect, inherence and reciprocal causal interaction are the rules on the basis of which we can know that objects actually exist indirectly, then we cannot know indirectly that external, spatially extended objects actually exist.

To understand how the Refutation of Idealism works as a response to the Indirect Realist Objection, it is important to notice that what Kant establishes in Refutation of Idealism is not just that we can know that external, spatially extended objects actually exist, but also that we can know this in a particular way, viz. directly. ${ }^{28}$ In his first remark on the Refutation of Idealism, Kant writes that '[the] immediate consciousness of the existence of outer things is in this theorem not presupposed, but proved' (B276). He also writes that '[idealism] assumed that the only immediate experience is inner experience, and that outer things could only be inferred from inner experience... But here it is proved that outer experience is really immediate' (B276). Kant's claim in this passage is that idealism is based on the assumption that we cannot know directly that external, spatially extended objects actually exist. And this is what the Refutation of Idealism establishes is 
false. ${ }^{29}$ This is also clear from Kant's argument in the Refutation of Idealism, which concludes: 'the consciousness of my own existence is at the same time an immediate consciousness of the existence of other things outside me' (B276, my emphasis)..$^{30}$ Now, one of the premises of the Indirect Realist Objection is precisely that we cannot know directly that external, spatially extended objects actually exist. So the Refutation of Idealism establishes that one of the premises of the Indirect Realist Objection is false. It is not only a Refutation of Idealism, but also a refutation of indirect realism. This is how it serves as a response to the Indirect Realist Objection against the Second Postulate.

So far in this section I have outlined the Indirect Realist Objection against the Second Postulate, and I have explained how the Refutation of Idealism works as a response to this objection. At this point, I am going to argue that this is plausibly the objection to which Kant is referring in his explanation for the location of the Refutation of Idealism at the end of his elucidation of the Second Postulate. Kant's claim in the relevant sentence is that '[a] powerful objection against these rules for proving existence indirectly is made by idealism, the refutation of which is here in its right place' (B274). Now part of the Second Postulate is the claim that the laws of cause and effect, inherence and reciprocal interaction are the rules for proving existence indirectly. So as I explained in Section II, it is a reasonable assumption that what Kant means by a powerful objection against 'these rules for proving existence indirectly' is a powerful objection against the laws of cause and effect, inherence and reciprocal interaction. But there is another reasonable interpretation of this part of Kant's claim. It may be that what Kant means by a powerful objection against 'these rules for proving existence indirectly' is not an 
objection against the laws of cause and effect, inherence and reciprocal interaction, but rather an objection against the claim that the laws of cause and effect, inherence and reciprocal interaction are the rules for proving existence indirectly. It may be that what Kant means by a powerful objection against these rules for proving existence indirectly is not an objection against the particular principles that he has just specified as the rules for proving existence indirectly, but rather an objection against his specification of these principles in particular as the rules for proving existence indirectly.

As I also pointed out in Section II, it is a reasonable assumption that what Kant means by a powerful objection 'made by idealism' against a particular claim is an objection on the part of idealism. But again there is another reasonable interpretation. It may be that what Kant means by a powerful objection 'made by idealism' against a particular claim is not the objection that this claim must be false since idealism is true but rather the objection that this claim must be false since otherwise idealism is true. There is a clear sense in which an objection along these lines counts as an objection 'made by idealism'.

Putting these points together, it is reasonable to interpret Kant's reference to a 'powerful objection against these rules for proving existence indirectly... made by idealism' as a reference to the objection that the part of the Second Postulate that specifies the rules for proving existence indirectly must be false, since otherwise idealism is true. This is the precisely the force of the Indirect Realist Objection. The Indirect Realist Objection establishes that if the laws of cause and effect, inherence and reciprocal causal interaction are the rules for proving existence indirectly, then we cannot know that 
external, spatially extended objects actually exist - this is premise (4) of the objection and then concludes on the basis of this and the assumption that we can know that external, spatially extended objects actually exist - premise (5) of the objection - that the laws of cause and effect, inherence and reciprocal causal interaction are not the rules for proving existence indirectly.

I propose that Kant adds the Refutation of Idealism to the second edition of the Critique at the end of his elucidation of the Second Postulate of Empirical Thinking in General precisely because it is his response to the Indirect Realist Objection. The end of the elucidation of the Second Postulate is the appropriate place for Kant's response to the Indirect Realist Objection, since the target of this objection is the Second Postulate - and, in particular, the part of the Second Postulate that specifies the rules for proving existence indirectly. Moreover, the Refutation of Idealism works as a response to the Indirect Realist Objection, since it establishes that one of the premises of the objection, viz. the claim that we cannot know directly that external, spatially extended objects actually exist, is false. Finally, this explanation for the location of the Refutation of Idealism is plausibly expressed by the sentence that Kant adds at the end of his elucidation of the Second Postulate, since there is a clear sense in which the Indirect Realist Objection counts as an objection 'against these rules for proving existence indirectly... made by idealism' (B274). I conclude that this explanation for the location of the Refutation of Idealism is superior to the explanations that I discussed in previous sections of this article.

\section{$\S 5$. THE REFUTATION OF IDEALISM}


It might be asked what advantages this explanation has in terms of helping us to understand Kant's Refutation of Idealism. In the remainder of this paper, I am going to describe two such advantages. The first advantage of this explanation is that it helps us to understand how the Refutation of Idealism works as a response to the claims about the Critique in the famous Göttingen Review. The Göttingen Review was a brief critical summary of the first edition of the Critique drafted by Christian Garve, edited by Johann Georg Heinrich Feder, and published in 1782 in a supplement to the Göttingische Anzeigen von gelehrten Sachen. ${ }^{37}$ The Göttingen Review describes the Critique as a 'system of higher... idealism', which 'transforms the world and ourselves into representations' ${ }^{38}$ It ascribes to Kant the claim that 'everything of which we can know and say something... is merely representation and law of thought', and that 'representations in us, modified and ordered in accordance with certain laws are just that which we call object and world'. ${ }^{39}$ It concludes on this basis that, in spite of his protestations to the contrary, Kant is an idealist. Idealism, according to the Göttingen Review, is an implication of the claims to which Kant is committed.

It is widely accepted that many of Kant's modifications to the second edition of the Critique, including the addition of the Refutation of Idealism at the end of the elucidation of the Second Postulate, were intended as a response to the Göttingen Review. Ralf Bader writes that the addition of the Refutation of Idealism 'probably occurred due to historical reasons as Kant wanted to avoid the charge made by the Feder-Garve review... that his theory was... a system of "idealism that encompasses spirit and matter in 
the same way, and transforms the world and us into representations"' (2012: 54). Similarly, Giuseppe Motta writes that 'the reason for this not insignificant change... was the necessity of supplying as precise and well-structured as possible a response to the objections that, in particular, Johann Georg Heinrich Feder had voiced on the basis of the revision of an original text by Christian Garve in an anonymously published review of the Critique' (2012: 117). If this is correct, then we should expect the aim of the Refutation of Idealism to be to establish that the truth of idealism is not an implication of the claims to which Kant is committed. And this is indeed the case according to the explanation for the location of the Refutation of Idealism that I introduced in Section IV. The Refutation of Idealism is Kant's response to an objection that purports to show that a particular claim to which he is committed, viz. the Second Postulate - and, in particular, the claim that the laws of cause and effect, inherence and reciprocal interaction are the rules for proving existence indirectly - implies that idealism is true. So my explanation helps us to understand how the Refutation of Idealism works as a response to the Göttingen Review.

Compare any of the other explanations for the location of the Refutation of Idealism that I considered in Sections II and III of this article. These explanations treat Kant's Refutation of Idealism as a response to an objection against the laws of cause and effect, inherence and reciprocal interaction, or the Second Postulate, based on the premise that idealism is true. But there is no objection of this sort in the Göttingen Review. The reviewers do not object to the Critique on the grounds that it fails to refute idealism and therefore leaves open the possibility of an objection to the laws of cause and effect, inherence and reciprocal interaction, or the Second Postulate, based on the premise that 
idealism is true. As Frederick Beiser puts it, the Göttingen Review is 'a hostile polemic that judge[s] the [Critique] from the standpoint of the philosophy of common sense' (2002: 89). It is not a hostile polemic against the Critique from the standpoint of the philosophy of idealism. On behalf of the other explanations that I discussed in Sections II and III it may be suggested that the Refutation of Idealism still works as a response to the objection in the Göttingen Review since it makes it clear that Kant is committed to the claim that idealism is false. The trouble with this suggestion is that it doesn't follow from the fact that Kant is committed to the claim that idealism is false that it is not also an implication of the claims to which he is committed that idealism is true. Suppose that the reviewers object that it is an implication of the claims to which Kant is committed that idealism is true, and that Kant's response is to insist that he is committed to the claim that idealism is false. The reviewers need not conclude on this basis that their objection was mistaken. They may conclude instead that Kant's position is contradictory. If Kant wishes to respond to the objection in the Göttingen Review, what he needs to show is not that he is committed to the claim that idealism is false, but rather that it is not an implication of the claims to which he is committed that idealism is true. This is precisely what he is doing in the Refutation of Idealism according to the explanation that I introduced in Section IV.

My explanation also sheds light on Kant's argumentative strategy in the Refutation of Idealism. As I mentioned in Section IV, Kant's argument establishes that we are immediately conscious of external, spatially extended objects. It establishes that 'the determination of my existence in time is possible only by means of the existence of 
actual things that I perceive outside myself (B275-276, my emphasis). If my explanation is correct, then it is possible to understand why it is so important to Kant to establish not only that we can know that external, spatially extended objects actually exist, but also that we can perceive objects of this sort. Kant's aim in the Refutation of Idealism is to respond to an objection against the claim that the laws of cause and effect, inherence and reciprocal interaction are the rules for proving existence indirectly. In particular, his aim is to respond to the objection that this claim must be false since otherwise we cannot know that external, spatially extended objects actually exist. And the objection in question is based on the assumption that we cannot know directly that external, spatially extended objects actually exist, which is to say, the assumption that we cannot perceive objects of this sort. So Kant's response is to show that we can perceive external, spatially extended objects. In this way, the explanation that I have introduced in this article also helps us to understand Kant's argumentative strategy in the Refutation of Idealism.

\section{\$6. CONCLUSION}

In the course of this article I have defended an explanation for the location of Kant's Refutation of Idealism that differs significantly from other explanations in the recent secondary literature. What these other explanations have in common is the assumption that Kant inserts the Refutation of Idealism at the end of his elucidation of the Second Postulate because he thinks that this is the appropriate place to respond to an objection against the Second Postulate on the part of idealism. I have argued that this assumption 
is false. In particular, I have argued that the objection that worries Kant is not that the Second Postulate must be false since idealism is true, but rather that the Second Postulate must be false since otherwise idealism is true. I have argued that what Kant has in mind is the Indirect Realist Objection against the Second Postulate. This explanation for the location of the Refutation of Idealism is plausibly expressed by the sentence that Kant inserts at the end of his elucidation of the Second Postulate. It sheds light on the argumentative strategy of the Refutation of Idealism, as well as its relationship to the

concerns expressed in the Göttingen Review. It also requires a substantial change to the way that we understand the broader purpose of this important section of the Critique of Pure Reason.

\section{REFERENCES}

- Allison, H.E. (2004), Kant's Transcendental Idealism: An Interpretation and Defense: Revised and Enlarged Edition. New Haven CT: Yale University Press.

- Bader, R.M. (2012), 'The Role of Kant's Refutation of Idealism', Archiv für Geschichte der Philosophie, 94: 53-73.

- Bennett, J. (1966), Kant's Analytic, Cambridge: Cambridge University Press.

- Beiser, F.C. (2002), German Idealism: The Struggle Against Subjectivism: 17811801, Cambridge MA: Harvard University Press.

- Caranti, L. (2007), Kant and the Scandal of Philosophy: The Kantian Critique of Cartesian Scepticism. Toronto: Toronto University Press. 
- Friedman, M. (2013), Kant's Construction of Nature: A Reading of the Metaphysical Foundations of Natural Science. Cambridge: Cambridge University Press.

- Guyer, P. (1987), Kant and the Claims of Knowledge, Cambridge: Cambridge University Press.

- Guyer, P. (1998), 'The Postulates of Empirical Thinking in General and the Refutation of Idealism' in G. Mohr and M. Willaschek (eds.) Immanuel Kant: Kritik der reinen Vernunft. Berlin: Akademie Verlag.

- Heidemann, D.H. (1998), Kant und das Problem des metaphysichen Idealismus. Berlin: Walter de Gruyter.

- Kant, I. (1998), Critique of Pure Reason: Translated and Edited by Paul Guyer and Allen. W. Wood. Cambridge: Cambridge University Press.

- Motta, G. (2012), Die Postulate des empirischen Denkens überhaupt: KrV A218235/B265-287: Ein kritischer Kommentar. Berlin: Walter de Gruyter.

- Sassen, B. (ed.) (2000), Kant's Early Critics: The Empiricist Critique of the Theoretical Philosophy. Cambridge: Cambridge University Press.

- Strawson, P.F. (1966), The Bounds of Sense: An Essay on Kant's Critique of Pure Reason. London: Methuen.

- Van Cleve, J. (1999), Problems from Kant. Oxford: Oxford University Press.

- Wolff, R.P. (1963), Kant's Theory of Mental Activity: A Commentary on the Transcendental Analytic of the Critique of Pure Reason. Cambridge MA: Harvard University Press. 
${ }^{1}$ All references to the Critique of Pure Reason take the standard A/B form. All other ${ }^{2}$ In the original: 'Einen mächtigen Einwurf aber wider diese Regeln, das Dasein mittelbar zu beweisen, macht der Idealism, dessen Widerlegung hier an der rechten Stelle ist' (B274).

${ }^{3}$ Heidemann writes that 'an enquiry concerning the Refutation of Idealism has to pose not only questions about the Kantian proof of the existence of the external world, but also the question about the location of the Refutation of Idealism within the Critique of Pure Reason' (1998: 94). Some commentators have concluded that there is no satisfactory answer to this question. Strawson writes that the Refutation of Idealism is 'not very strategically placed in the middle of the Postulates of Empirical Thought' (1966: 122). Bennett writes that the Refutation of Idealism 'is placed, for a silly reason, in the middle of [Kant's] discussion of the Postulates', even though 'it has more in common with the second Analogy of Experience' (1966: 166). Wolff writes: '[the Refutation of Idealism] has nothing especially in common with the teaching of the Postulates and I shall therefore treat it separately, taking the opportunity to connect it up with several related passages from other parts of the Critique' (1963: 293).

${ }^{4}$ In the original: 'Was mit den materialen Bedingungen der Erfahrung (der Empfindung) 
zusammenhängt, ist wirklich' (A218/B266).

${ }^{5}$ There are some alternative interpretations in the recent secondary literature. According to Giuseppe Motta, the Second Postulate implies that '[the] determination of the actuality of a thing requires always at the same time the matter of the senses and the form of the pure concepts of the understanding, for the thing can be determined in existence only on the basis of the lawfulness and necessity of experience' (2012: 116). Motta interprets the Second Postulate as an epistemological claim. But he appears to take this principle to imply that it is not sufficient for us to know that that an object actually exists that we have perceived it. He thinks that some sort of appeal to the Analogies of Experience is a necessary condition of knowing that an object actually exists. James Van Cleve appears to interpret the Second Postulate as a metaphysical claim. He writes that 'Kant is telling us that to be actual is to be either given in perception or causally connected with perception' (1999: 234). I find it hard to square these interpretations with the text of Kant's elucidation of the Second Postulate.

${ }^{6}$ Here it may be pointed out that, according to Kant, epistemological claims about the conditions under which we can know that objects fall under concepts and principles are closely connected to metaphysical claims about the conditions under which objects fall under these concepts and principles. I do not mean to deny that the Second Postulate can also be understood as a metaphysical claim about the conditions under which objects actually exist, at least if 'objects' means 'objects of experience' or 'objects insofar as we can know about them'. What matters for my purposes is just that, in the first instance, the Second Postulate is an epistemological claim. 
${ }^{7}$ According to Michael Friedman, the magnetic matter is an 'aether', which is affected by the presence of a magnet. The magnet 'causes the surrounding aether to be put into a certain state, which then causes the attracted iron filings to move - presumably by some kind of pressure' (2013: 357).

${ }^{8}$ It may be objected that this implication is perfectly acceptable. I cannot be certain that there is a person outside pressing the button if I simply hear the doorbell, since the cause could be a malfunction in the doorbell mechanism. In response to this objection, I should point out that what I have been interpreting as Kant's claim about the necessary conditions of being able to know that an object actually exists is in fact a claim about the necessary conditions of having cognition of the actual existence of an object. I have ignored the distinction between knowledge and cognition for the sake of simplicity, but it is generally accepted that the two are very different (e.g. Watkins and Willaschek, unpublished manuscript). In particular, there is no reason to think that cognition involves certainty. While Kant might accept that I cannot be certain that there is a person outside pressing the button if I simply hear the doorbell, he would allow for the possibility that I have cognition that there is such a person.

${ }^{9}$ I would like to thank an anonymous reviewer for the European Journal of Philosophy for preventing me from running together these very different ways of thinking about the Second Postulate. The argument I have given against the first interpretation is a variation on one that he/she suggested.

${ }^{11}$ The sort of idealism that Kant refutes in his Refutation of Idealism is what he calls problematic idealism. He defines this at the beginning of the Refutation of Idealism as 'the 
theory that declares the existence of objects in space outside us... to be doubtful and unprovable' (B274). In the first edition of the Critique Kant defines this sort of idealism, which he calls sceptical idealism (A377), as the theory of the uncertainty of 'the existence of all objects of outer senses' (A367).

${ }^{12}$ Ralf Bader writes: 'Occasionally commentators simply state that the Second Postulate is concerned with what is actual and that Kant wants to show in the Refutation that external objects are actual... While this is correct, there is more to be said and one ought to take seriously what he himself says, namely that idealism raises a serious objection to the arguments of the Second Postulate, insofar as it poses "what is a serious objection to these rules for proving existence mediately"' (2012: 67).

${ }^{13}$ The same objection applies to Paul Guyer's explanation for the location of the Refutation of Idealism. He writes that 'Kant's motivation for inserting [the Refutation of Idealism] in the Postulates rather than elsewhere in the Critique can be understood as an attempt to complement the arguments already considered: on the one hand, the section on the postulates is intended to argue that the categories of possibility and necessity have no gainful employment outside the sphere of experience; on the other hand, Kant will now argue that our experience of the actual itself is an experience of the existence of objects other than our own representations that can be secured from the threats of skepticism and traditional idealism' (1998a: 308-309). There is a similar passage in the introduction to Guyer and Wood's translation of the first Critique. They write that '[this] may seem like an inauspicious location for such an addition, but Kant's intention in choosing it can only have been to show that empirically meaningful judgments about the 
modalities of possibility and necessity all depend upon connection to the actual in perception, and then to show what he means by the actual in perception: that which we judge to exist independently of our representation of it, even if we also know that the form in which we represent the independence of such objects is itself dependent upon the constitution of our own sensibility' (1998b: 71). Guyer thinks that the implication of the Refutation of Idealism is that the objects that we know actually exist do include objects other than representations in our minds. Whereas the Second Postulate establishes that our knowledge of the actual existence of objects is restricted to what we have experienced, the Refutation of Idealism establishes that our knowledge of the actual existence of objects is not restricted to representations in our minds. Guyer thinks that this shared concern of the Refutation of Idealism and the Second Postulate with the extent of our knowledge of the actual existence of objects is the only possible explanation for the location of the Refutation of Idealism. The trouble is that this explanation is not plausibly expressed by the sentence that Kant inserts at the end of his elucidation of the Second Postulate.

${ }^{14}$ Both Luigi Caranti and Henry Allison think that this explanation for the location of the Refutation of Idealism is the one expressed by the sentence that Kant inserts at the end of his elucidation of the Second Postulate. Allison writes that Kant's 'stated justification for placing the Refutation in this context is that idealism "poses a powerful objection against these rules" (B274)', which 'suggests that the dispute with idealism is directly concerned with the validity of these rules, or, more precisely, the a priori principles on which they are based' (2004: 286). Caranti writes that '[the] reason given by Kant for placing the Refutation after the Second Postulate is that Cartesian idealism poses "a serious objection 
to these rules for proving existence mediately" (B274)', which 'invites us to think that the disagreement between him and the sceptic is about specific rules for inferring the existence of external objects' (2007: 129).

on insists that this thesis is 'far from the overall conclusion at which the argument [of the First Analogy] aims' (2004: 239).

${ }^{16}$ In the First Analogy, A182 and B224, in the Second Analogy, A189/B232, and in the Third Analogy, A211/B256.

${ }^{18}$ Heidemann writes: 'Kant shows in the Refutation of Idealism that the existence of the external world is provable on the basis of a law that governs the necessary connection of our experience, namely on the basis of the principle of persistence' (1998: 98). Guyer writes that 'the argument for the connection between permanence and timedetermination on which Kant obviously means to rely... is, of course, the first Analogy of Experience' (1987: 283). Allison disagrees. He writes that the Refutation of Idealism 'relies only on one portion of the progressive argument of the first Analogy, namely, the backdrop thesis' (2004: 291), by which he means the principle that 'an enduring, perceivable object (or objects) is required to provide the backdrop or frame of reference by means of which the succession, simultaneity, and duration of appearances in a common time can be determined' (2004: 239). Allis

${ }^{21}$ Like Caranti, Allison rejects Kant's 'stated justification' for the location of the Refutation of Idealism in the sentence that he inserts at the end of his elucidation of the Second Postulate. He writes: '[A] more plausible interpretation of Kant's explanation is that the idealist's challenge is to the premise underlying the applicability of these rules 
rather than to the rules themselves. What the idealist questions is the assumption that being connected with sensation (a mental occurrence) is a reliable mark of actuality with regard to the external world. (2004, 286-287).' Again, like Caranti, Allison thinks that the idealist objects to the claim that it is sufficient for us to know that an object actually exists that we have perceived it. Allison's language is almost identical to Caranti's. While Allison's discussion of the location of the Refutation of Idealism precedes Caranti's by three years, Allison writes in an endnote that his position is influenced by Caranti's 2001 dissertation The Development of Kant's Refutation of Idealism (2004: 494).

${ }^{22}$ To this Bader might respond that, as far as Kant is concerned, these conditions are satisfied by internal objects only if they are also satisfied by external objects. Now, this may well be true. But it isn't relevant. The question is not whether Kant subscribes to the premise that the Second Postulate is relevant only if idealism is false, but whether an idealist objecting to Kant would subscribe to this premise, and so argue that since idealism is true, the Second Postulate is irrelevant.

${ }^{23}$ This is a highly selective treatment of Bader's nuanced and complex discussion of the location of Kant's Refutation of Idealism. One of Bader's most interesting proposals is that the Refutation of Idealism is Kant's response to an objection against the applicability, or external validity, of the Principles of Pure Understanding in General, where a principle is applicable or externally valid if and only if there are external, spatially extended objects to which it applies. I have neglected this aspect of Bader's discussion because while it might explain why Kant inserts the Refutation of Idealism into the System of Principles, it doesn't explain why he inserts the Refutation of Idealism at the end of his elucidation of 
the Second Postulate. Nor does Bader present it as an explanation of this fact.

${ }^{24}$ I would like to express my gratitude to an anonymous reviewer for the European Journal of Philosophy for suggesting this alternative explanation for the location of the Refutation of Idealism.

${ }^{25}$ At the beginning of the second chapter of the Analytic of Principles, Kant raises the question how synthetic judgments a priori are possible. His answer to the question is that '[the] possibility of experience is that which gives all of our cognitions a priori objective reality' (A156/B195). He also writes that '[in] this way are synthetic judgments a priori possible, if we... say: the conditions of the possibility of experience in general [my emphasis] are at the same time conditions of the possibility of objects of experience, and therefore have objective validity in a synthetic judgment a priori' (A158/B197).

${ }^{26}$ When Kant first introduces his answer to the question how synthetic judgments $a$ priori are possible in the second chapter of the Analytic of Principles, he remarks that in a synthetic judgment a priori, 'a third thing is necessary, from which alone the synthesis of the two concepts can result'. He then explains what this 'third thing' consists in: '[there] is only one totality, in which all our representations are contained, namely inner sense, and the form of inner sense a priori, time. The synthesis of the representations depends rests on the imagination, but the synthetic unity of the representations (which is required for judgment), on the unity of apperception' (A155/B194). Here Kant appears to identify the 'third thing' that is involved in synthetic judgments a priori with the possibility of experience in general, the sensible form of which is time, not with the possibility of outer experience, the sensible form of which is space. 
${ }^{27}$ This echoes a point that Kant makes (or, rather, that the idealist makes and that Kant accepts) in the Fourth Paralogism in the first edition of the Critique: 'in the relation of perception to its cause, it always remains doubtful whether this cause is internal, or external' (A368).

${ }^{28}$ I should stress that it doesn't follow from the claim that we can know that external, spatially extended objects actually exist directly, that the Analogies of Experience are entirely redundant as far as our knowledge of the actual existence of external, spatially extended objects is concerned. There may still be some external, spatially extended objects - Kant's 'magnetic matter', for example - that we can know actually exist only indirectly. I am grateful to an anonymous referee for the European Journal of Philosophy for prompting me to clarify this point.

${ }^{29}$ Kant's aim in his treatment of idealism in the Fourth Paralogism in the first edition of the Critique is also to establish that we know directly that external objects actually exist. He writes: 'I have as little need to infer the existence of external objects as I do to infer the existence of the objects of my inner sense (my thoughts)' (A371). He also indicates that a realist 'concedes to matter $[\ldots]$ an existence that need not be inferred, but is immediately perceived' (A371).

${ }^{30}$ Michael Friedman writes that the suggestion 'that the existence of outer objects would need to be proved by some kind of mediate inference' from the existence of other objects 'is precisely what the refutation of idealism denies' (2013: 584). Luigi Caranti writes that 'idealism questions... the immediacy of outer perception', and that the question whether outer perception is direct or indirect is the 'main point of disagreement' between idealists 
and their opponents (2007: 130). However, Caranti also claims that Kant fails to make it clear in the Refutation of Idealism that idealism questions... the immediacy of outer perception'. He suggests that this because Kant 'is trying to avoid a direct confrontation with the sceptic on the issue of the immediacy/mediacy of outer perception' (2007: 130). I find this implausible since Kant makes it perfectly clear in the lines that I have quoted that the key question is whether or not we know directly that external objects actually exist.

${ }^{37}$ For the historical background, see Sassen (2000).

${ }^{38}$ Sassen (2000:53).

${ }^{39}$ Sassen (2000:58). 